\title{
Identificación de los factores de atracción de fauna en las proximidades del AeropuertoToncontín
}

Alex Geovanni Matamoros

Carlos Alberto Torres

\section{Resumen}

La fauna, sobre todo las aves, representan un peligro latente para la aviación especialmente en aquellos ambientes que cuentan con vegetación, agua o fuentes de alimentación para animales que puedan provocar incidentes 0 accidentes en las operaciones aeronáuticas. Los episodios sobre todo de accidentes provocados por animales no suman grandes cantidades de casos en la industria aeronáutica, pero cuando se dan causan pérdidas multimillonarias y aun muertes, de aquí la importancia de examinar el fenómeno. En particular el presente trabajo propone una caracterización de los sitios de atracción de fauna silvestre con potencial de afectación a las operaciones de las aeronaves en el Aeropuerto Internacional Toncontín en su zona perimetral.

Esta investigación se limita a la recolección de alguna de la abundante bibliografía existente sobre el tema y a la propuesta de unos elementos metodológicos que pueden ayudar a encuadrar el tema del peligro aviar y de fauna en la zona indicada; para tener un estudio que incorpore datos de campo se requiere de más tiempo y sobre todo de la colaboración en todo el proceso de investigación de un equipo integrado por especialistas del campo de la biología que profundicen en una serie de temas que sólo fueron mencionados. Se muestra que el principal peligro aviar en el aeropuerto Internacional Toncontín se da por los zopilotes (Coragyps atratus); lo cual no significa que no haya peligros latentes por la presencia de otras especies de menor tamaño y peso que llegan a las cercanías y al recinto del aeropuerto en busca de alimentación, agua y refugio.

Palabras clave: peligro aviar, accidente, incidente, recinto aeroportuario. 


\section{Abstract}

Wildlife, especially birds, represent a danger for aviation especially in environments that have vegetation, water or power supplies for animals that may provoke incidents or accidents in aviation operations. The episodes especially of accidents caused by animals not add large numbers of cases in the aviation industry, but when they cause multibillion-dollar losses and even deaths, hence the importance of examining the phenomenon. In particular, this paper proposes a characterization of attraction sites of wildlife potentially affected to aircraft operations at the airport Toncontin and his perimeter area.

This research is limited to the collection of some of the abundant literature on the subject and proposed a methodological elements that can help frame the issue of endangered bird and wildlife in the defined area; to have a study incorporating field data requires more time and especially collaboration throughout the research process integrated by specialists in the field of biology that delve into a number of issues that were just mentioned. It is shown that the main animal risk in Toncontin International Airport is the Coragyps atratus (zopilote); nevertheless are also a risk other species of smaller size and weight that reach the airport in search of food, water and shelter..

Keywords: bird danger, accident, incident, airport grounds

Alex Geovanni Matamoros, (algemaca@hotmail.com), Departamento de Ciencias Aeronáuticas,Facultad de Ciencias Espaciales, Universidad Nacional Autónoma de Honduras - UNAH. Carlos Alberto Torres ,(kriegsmarine21@gmail.com), Departamento de Ciencias Aeronáuticas,Facultad de Ciencias Espaciales, Universidad Nacional Autónoma de Honduras - UNAH 


\section{Introducción}

El Diplomado en Sistemas Aeroportuarios desarrollado el primer semestre de 2014 en Toncontín, por el Departamento de Ciencias Aeronáuticas en el Aeropuerto Internacional Toncontín, se propuso cinco temas de investigación en base a los cuales se elaboraron como requisito de egreso el mismo número de investigaciones. Dada su relevancia, uno de los temas abordados fue el del peligro que representa la fauna presente dentro y en el entorno del aeropuerto Toncontín.

El trabajo de investigación presentado en este artículo, examina el peligro mencionado partiendo de una revisión de la literatura sobre el tema, de los datos obtenidos en un recorrido en el entorno del aeropuerto y de la información brindada por el biólogo encargado del por parte de Aeropuertos de Honduras.

El cuerpo de trabajo se puede dividir en tres partes; en primer lugar se explica que la metodología del estudio propuesto es exploratorio, se proponen las categorías con las que se examina el fenómeno analizado y se proponen las fases que se desarrollaron para la elaboración de la investigación; un segundo bloque propone de forma resumida dos de los resultados obtenidos, se trata de un mapa de zonas con atractivo para la fauna del Aeropuerto de Toncontín y de una serie de fotografías de la flora existente en el recinto aeroportuario con información sobre sus características y sobre la fauna que estas zonas verdes pueden atraer; el tercer bloque lo conforman un serie de conclusiones que se derivan de los resultados obtenidos.

El tema del peligro por fauna en Toncontín requiere para su análisis y elaboración de propuestas de mitigación, del trabajo coordinado de un equipo interdisciplinario de profesionales que combinen el conocimiento profundo del entorno y las operaciones aeroportuarias con el manejo de las dinámicas de los ecosistemas que subsisten en este recinto aeroportuario. Por esta razón este artículo, más que constituirse en una propuesta de intervención, ofrece una primera aproximación al tema, desde la cual se pueden establecer nuevas metodologías de tratamiento del problema y una serie de nuevos aspectos a indagar para orientar el trabajo interinstitucional necesario para reducir las posibilidades de incidentes y accidentes en la zona investigada. 


\section{Objetivos}

\section{Objetivo General}

Caracterizar los sitios de atracción de fauna silvestre con potencial de afectación a las operaciones de las aeronaves en el Aeropuerto Internacional en su zona perimetral.

\section{Especificos}

- Localizar los sitios que pueden generar peligro en las operaciones aéreas en el Aeropuerto Internacional Toncontin.

- Describir los factores de atracción de fauna silvestre identificados.

\section{Método}

La investigación se propone un enfoque cualitativo por cuanto se profundizará en algunas de las características de los sitios de atracción de fauna, que pueden afectar negativamente las operaciones aéreas del Aeropuerto Internacional Toncontín.

Se propuso un estudio exploratorio puesto que si bien el fenómeno, sobre todo del peligro aviar ha sido estudiado para otros aeropuertos del mundo; para el caso del Aeropuerto Internacional Toncontín se puede afirmar que es un "tema 0 problema de investigación poco estudiado del cual se tienen muchas dudas o no se ha abordado antes" (Sampieri, 2006, p.101).

Las principales categorías utilizadas en la aplicación de los distintos instrumentos de consulta son las siguientes:

- Aeródromo: Área definida de tierra, que incluye todas sus edificaciones, instalaciones y equipos, destinada total o parcialmente a la llegada salida y movimiento en superficie de aeronaves (Dirección General de Aeronáutica Civil , 2008, RAC 139.5 Acrónimos y Definiciones y Abreviaturas).

- Factores de atracción: elementos que al proveer de recursos que cubren sus necesidades, atraen la presencia de fauna (basureros, áreas verdes, áreas de almacenaje, acuíferos).

- Franja de calle de rodaje: Zona que incluye una calle de rodaje, destinada a proteger a una aeronave que esté operando en ella y a reducir el riesgo 
de daño en caso de que accidentalmente se salga de esa área (RAC 139.5 Acrónimos y Definiciones y Abreviaturas).

- Franja de pista: Superficie definida que comprende la pista y la zona de parada, si la hubiese, destinada a: (a) reducir el riesgo de daños a las aeronaves que se salgan de la pista; y (b) proteger a las aeronaves que la sobrevuelan durante las operaciones de despegue o aterrizaje (RAC 139.5 Acrónimos y Definiciones y Abreviaturas).

- Incidente: Todo suceso relacionado con la operación de un avión, distinto de un accidente, que afecte o pueda afectar a la seguridad de las operaciones (RAC 139.5 Acrónimos y Definiciones y Abreviaturas).

- Incidente grave: Cualquier incidente en el que concurran circunstancias que indiquen que casi estuvo a punto de producirse un accidente. La diferencia entre accidente e incidente grave estriba solamente en el resultado (RAC 139.5 Acrónimos y Definiciones y Abreviaturas).

- Incidente de superficie: Cualquier evento que ocurra a consecuencia de un movimiento no autorizado dentro del área de movimiento, o una ocurrencia en el área de movimiento asociada con la operación de una aeronave, en que se afecte o pueda verse afectada la seguridad operacional (RAC 139.5 Acrónimos y Definiciones y Abreviaturas).

- Accidente: Todo suceso relacionado con la utilización de una aeronave, que ocurre dentro del periodo comprendido entre el momento en que una persona entra a bordo de una aeronave con la intención de realizar un vuelo y el momento en que todas las personas han desembarcado, durante el cual: (a) Cualquier persona sufra lesiones mortales o graves como resultado de hallarse en la aeronave, entrar en contacto con alguna parte del avión, por exposición directa al chorro de un reactor en determinadas circunstancias (b) La aeronave sufra daños o roturas estructurales que alteren de manera adversa sus características de resistencia estructural, de performance o sus características de vuelo, y que exigirían normalmente una reparación mayor, (c) La aeronave desaparece o es totalmente inaccesible (RAC 139.5 Acrónimos y Definiciones y Abreviaturas).

- Incursiones en pista: Cualquier ocurrencia en un aeródromo que involucre una aeronave, un vehículo, personas u objetos en tierra, que puedan crear un riesgo de colisión o pérdida de separación con una aeronave en despegue, carreteo, aterrizaje o en intento de aterrizaje. Instalaciones y equipo de aeródromo. 
Instalaciones y equipo, dentro de los límites de un aeródromo o fuera de estos, construidos o instalados y mantenidos para la llegada, salida y movimiento en superficie de aeronaves (RAC 139.5 Acrónimos y Definiciones y Abreviaturas).

- Medidas de mitigación: medidas que eliminan el peligro potencial o que reducen la probabilidad o severidad del riesgo.

- Peligro aviario y de fauna silvestre: El peligro potencial de daño a la aeronave por la colisión con aves o animales dentro o en las cercanías del aeródromo (RAC 139.5 Acrónimos y Definiciones y Abreviaturas).

- Priorización de riesgos: es el orden de importancia que tienen los posibles riesgos que se pueden dar en las operaciones de un aeródromo.

Para situar geográficamente el ámbito de la investigación propuesta nos ocuparemos de lo que se conoce como Recinto Aeroportuario, retomando lo que propone la Agencia de Seguridad Aérea Española (Agencia Estatal de Seguridad Aérea, 2013. Pp. 6-8) como "el espacio delimitado por los terrenos aeroportuarios" cuyos requisitos son "a. Se caracterizará la totalidad de la superficie del recinto aeroportuario dividiéndolo en categorías detalladas de formaciones 0 hábitat (teselas), resaltando para cada una de ellas a qué tipo de fauna pueden acoger 0 favorecer. b. La descripción de teselas representativas de hábitats debe especificar sus características ecológicas de detalle en cuanto a su capacidad de albergar a unas determinadas especies. c. Se debe prestar una atención especial a las especies que produzcan granos, flores o frutos que sean un alimento atractivo, identificando su presencia en las teselas". Estas descripciones se harán de acuerdo a la disposición de los recursos de información y tiempo disponibles.

Por otra parte, en el Programa de reducción de impactos con fauna del Aeropuerto Internacional EI Dorado (OPAIN, S.A., 2010), se propondrá una identificación de los espacios con potencial de atracción para la fauna al cual sirve de base para la clasificación de espacios que hace el presente trabajo, dicha clasificación es la siguiente: zonas arboladas, zonas de regeneración secundaria, zonas verdes aeroportuarias, tanque de evaporación de meteorología, lugares de depósito y escombro, zonas urbanas, zonas urbanas residenciales, zonas urbanas industriales, zonas urbanas comerciales. Dada la naturaleza del objeto de estudio el equipo de investigación optó por una metodología prevalentemente cualitativa descriptiva que incluye la recolección de datos de campo. Básicamente se proponen tres fases: la construcción de un marco conceptual de referencia, la recolección de la información necesaria para hacer los análisis correspondientes y por último la generación 
del informe y su presentación. Con las fases definidas y discutidas en grupo, se establecieron los pasos específicos y el cronograma en base al cual se distribuyeron las responsabilidades a cada uno de los miembros del grupo.

FASE I: Definición de categorías de análisis. El tema del peligro aviar y de fauna forma parte del sistema de gestión de la seguridad operacional (SMS) en los aeropuertos y tiene qué ver con la presencia de animales que pueden ingresar en el área de movimiento y con las aves que vuelan en las áreas de aproximación. Otra información importante para la definición de las categorías de análisis utilizadas, es la relacionada con los basureros o botaderos que pueden atraer aves de carroña.

Fase II: Recolección de la información. Luego de establecer el marco de referencia se procedió a recolectar la información necesaria para dar fundamento teórico al trabajo de investigación. Se aplicó una guía de observación en el perímetro del Aeropuerto Internacional Toncontin en la que se recolectó información y se tomaron fotografías de aquellos elementos del recinto aeroportuario que pudieran tener algún atractivo para la fauna silvestre. Se entrevistó al experto en control de peligro aviario, con el que cuenta la Concesionaria InterAirports y que tiene su sede en San Pedro Sula. Esta fase comprendió los pasos de elaboración de los instrumentos de consulta y la aplicación de los mismos. Fase III: Presentación de la información. El aspecto más valioso de esta fase son las reflexiones del equipo de investigación con respecto a los resultados de los instrumentos aplicados y al marco de referencia propuesto. El desarrollo de las actividades de la fase nos dio la oportunidad de establecer un diálogo enriquecedor con profesionales técnicos del área, en donde ellos pudieron dar sus puntos de vista sobre los temas consultados, mientras nosotros partiendo de estas evidencias hicimos nuestras propias conclusiones en base a las cuales se pueden proponer alternativas de solución ante la problemática identificada. Los pasos de esta fase fueron la transcripción de los datos obtenidos, la elaboración del informe de investigación y la presentación del informe para su defensa pública.

\section{Resultados}

En esta parte de la investigación se proponen básicamente dos resultados a partir de los cuales se proponen las conclusiones, el primero es la zonificación del Aeropuerto Internacional Toncontín, el segundo la identificación de aquellos elementos que pueden representar algún atractivo para la presencia de aves y otro tipo de fauna que pueda representar un peligro para las aeronaves que operan en el Aeropuerto. 
En primer lugar se debe aclarar que el presente estudio no ha hecho un conteo del número de individuos de la cada una de las especies con presencia en la zona del aeropuerto como lo propone la $\mathrm{OACl}$ cuando explica que el mejor método para determinar qué ave puede constituir un peligro es "contar el número individuos de esa especie que se hallen presentes o predominen en la zona", así como aquellas que pasan por la zona (Organización para la Aviación Civil Internacional, 1991. Cap. 6 Clasificación de las aves en cuanto a riesgo potencial).

El documento citado también explica que cualquier ave por pequeña que esta sea constituye un peligro, este peligro aumenta mientras más grande es el ave y mientras mayor es el número de individuos que vuelan juntos y mientras más cerca están del aeropuerto y de las áreas en las que se mueven las aeronaves. En lo particular, este trabajo se enfoca, como ya se dijo en el recinto aeroportuario y en consecuencia examina las condiciones favorables para la presencia de toda fauna 0 avifauna en este ámbito. En este sentido retoma también el documento $\mathrm{OACl}$ (Cap. 7 Ordenación ambiental y modificación del terreno pp. 15-18) ya citado en donde se menciona que en un plan de ordenamiento ambiental se debe dar importancia a espacios que:

- pueden servir a las aves como fuente de alimentación cuando no se les da el tratamiento adecuado,

- sirven para la agricultura y en distintos momentos los productos sembrados atraen las aves,

- incluyen vertederos de basura que no están siendo manejados con las medidas de seguridad que disminuyan al máximo la presencia de aves que buscan estos lugares como fuente de alimentación.

- Contienen agua que pueden encontrarse en ríos, estanques, pozos o bien estancada en drenajes obstruidos u otros espacios similares.

- Quedan en la estructuras de los edificios o bien, en las zonas abiertas y que pueden servir de abrigo a roedores 0 aves.

- Tienen vegetación con plantas, árboles, flores y frutos que apetecen a distintos animales sobre todo a las aves. 


\section{Mapa con la caracterización de los espacios identificados}

Los animales acuden a los aeropuertos en busca de los elementos básicos para cumplir sus ciclos vitales como son: agua, alimento y lugares de refugio. En un entorno cambiante dado por el desarrollo e industrialización de las ciudades, los aeropuertos se convierten en un refugio de zonas verdes y remanentes de hábitat naturales supremamente atractivos para la fauna. Por lo tanto, el tipo de hábitat y usos del suelo son claves para determinar la presencia y abundancia de fauna en los aeropuertos. En el Aeropuerto Internacional Toncontín se reconocen las siguientes zonas que representan atractivos para la fauna:

\section{- Zonas Arboladas}

Corresponden a cercas vivas u otros elementos del paisaje que involucra la presencia de árboles dispersos, en una densidad inferior a la que presenta un bosque. El principal recurso que presta este hábitat es el de proveer estructuras para el descanso y la anidación de varias especies y el establecimiento de brechas de vigilancia para aves rapaces. La gran oferta de flores y frutos que presenta hace que este hábitat sea parte de la dinámica ecológica dando base y soporte a cadenas alimenticias completas.

\section{- Zonas de regeneración natural secundaria}

Se encuentran en estado de sucesión ecológica temprana, en la que sucede una regeneración natural con predominio de vegetación arbustiva y herbácea como pastos. La presencia de masas densas de arbustos altos y bajos en áreas de regeneración secundaria, proporcionan ambientes propicios para la presencia de fauna silvestre dentro del Aeropuerto: en términos alimenticios un gran atractivo para especies de aves granívoras; y por sus características estructurales provee refugio para ratones y conejos que induce a su vez atracción de grandes predadores.

\section{- Zonas verdes aeroportuarias}

Las zonas verdes corresponden en su gran mayoría, a áreas de seguridad como franjas de pista, zonas de final de pista o bermas de calles de rodaje. Son un hábitat bastante simplificado, ya que se requiere su constante mantenimiento para el cumplimiento de las diferentes normas aeronáuticas. Dentro de este hábitat se incluyen los canales de drenaje ya que la mayor parte de zonas verdes constan de estos. La vegetación de las zonas verdes aeroportuarias es disímil entre áreas, según el tiempo transcurrido entre podas y las características de drenaje del suelo. 
La vegetación en zonas bien drenadas exhibe la presencia de espigas e inflorescencias atractivas para insectos y especies granívoras e insectívoras.

- Tanque de evaporación meteorológica

Tanque de agua descubierto, ubicado en la estación de meteorología que presenta un atractivo natural para la avifauna como fuente de agua.

- Lugares de depósito de escombros y basura

Sitios donde se depositan desechos sólidos, si bien pueden conducir eventualmente a la aparición de aves oportunistas, no representan un verdadero foco de atracción al tiempo que no contengan materia orgánica. Puesto que principalmente contienen residuos sólidos no orgánicos, su efecto como focos no es considerable.

\section{- Zonas Urbanas}

El Aeropuerto Toncontín esta embebido en áreas urbanas con las que colinda por el norte, sur, este y oeste. Estas se caracterizan por la presencia de edificios 0 antenas y otras estructuras atractivas para las especies de aves más generalistas, es decir aquellas que se pueden nutrir de una amplia gama de fuentes alimenticias, las que se concentran en un espectro reducido de alimentos 0 tienen una única estrategia para conseguir comida son consideradas especialistas (Gill, 1995) . Muchas de estas estructuras suponen una excelente oferta de sitios de anidación. El hábitat urbano presenta una serie de coberturas y usos del suelo diferentes, que pueden ir desde el uso residencial hasta el industrial, todos ellos con diferentes implicaciones en términos de actividades que pueden representar un atractivo para la fauna en un momento dado. Los sectores residenciales pueden generar atractivo para la fauna especialmente por prácticas inadecuadas de limpieza que incluyen desde el barrido de las calles hasta el incorrecto manejo y recolección de residuos sólidos. Por otra parte, los atractivos más evidentes para la fauna peligrosa suelen encontrarse en las zonas industriales, donde se pueden desarrollar actividades como el proceso de productos cárnicos o derivados a nivel industrial. Aunque estas no parecen ser un tema de preocupación en las áreas aledañas al Aeropuerto Toncontín. 


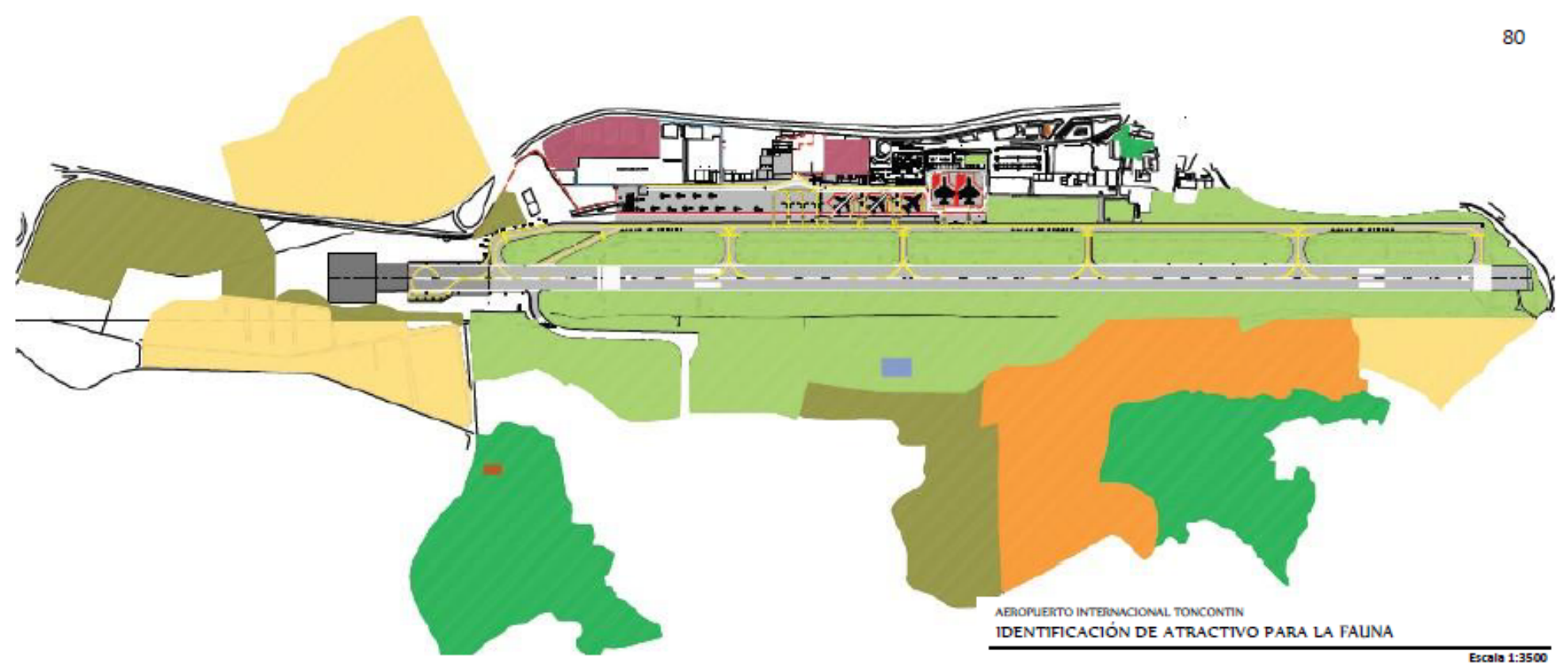

PLANO 1 ATRACTIVOS PARA LA FAUNA EN EL AEROPUERTO INTERNACIONAL TONCONTIN

RECINTO AEROPORTUARIO Y FRANIA CIRCUNDANTE

\section{ZONAS ARBOLNAS}

ZONUS DE RECENARUOON NATURAL. SECUNDARAA
ZONUS VERDES AERORORTUNRIAS
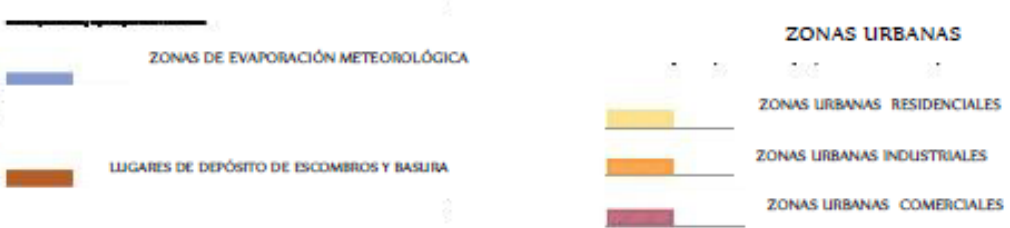


\section{Tipos de vegetación presentes en el entorno y aves que pueden atraer}

Foto 1: Familia Myrtacea: Familia muy extensa formada por gran número de plantas leñosas que van desde matas hasta grandes árboles. Tienen hojas persistentes, simples, enteras, generalmente opuestas, provistas de glándulas aromáticas, con consistencia coriácea muchas veces. Flores regulares, bisexuales, en inflorescencias de tipo cima, umbela, racimo o panícula, raras veces solitarias. Cáliz constituido generalmente por 4-5 lóbulos libres o a veces más o menos soldados, en ocasiones formando una caperuza (opérculo) que tapa al capullo y que se desprende al abrirse la flor. Corola constituida por 4-5 pétalos libres, pequeños y orbiculares, pocas veces soldados. Estambres numerosos, rara vez menos de 20, pudiendo constituir fascículos. Fruto generalmente en baya o cápsula, pudiendo contener de 2 a numerosas semillas (Árboles ornamentales, 2014).

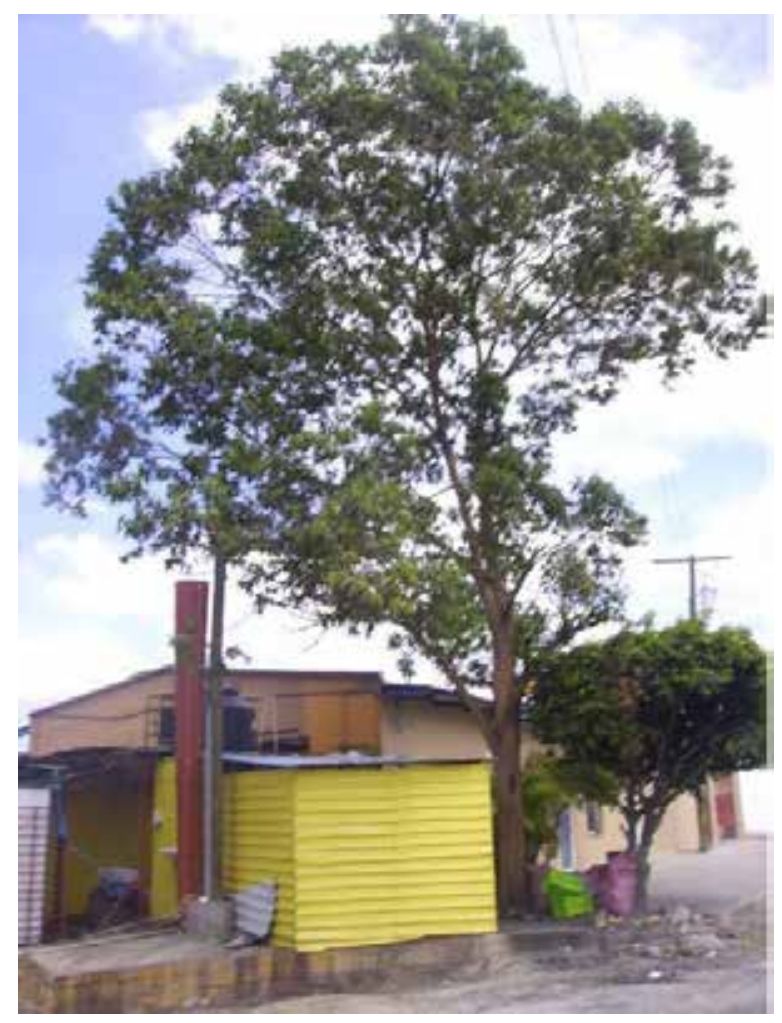

Foto 1. Tomada detrás del establecimiento "Pollos Yamal", frente al Boulevard Comunidad Europea. 
Animales que atrae: Animales Atraídos

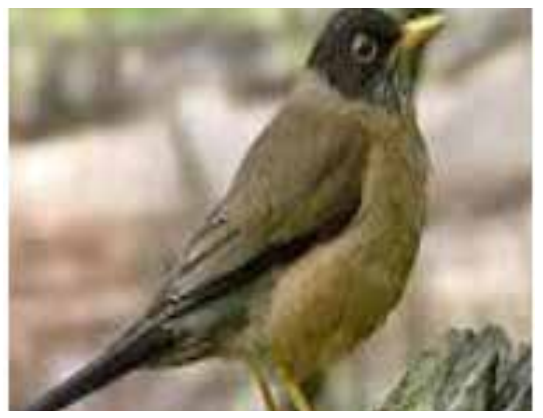

Foto 1

Figura 1: Zorzal (Turdus grayi): Es una especie de ave paseriforme de la familia Turdidae, común en América Central, aunque se encuentra desde el sur de Texas y México hasta Colombia. Posee un canto de varias tonalidades que es similar al del ave lira, debido a que toma sonidos que escucha para componerlo.

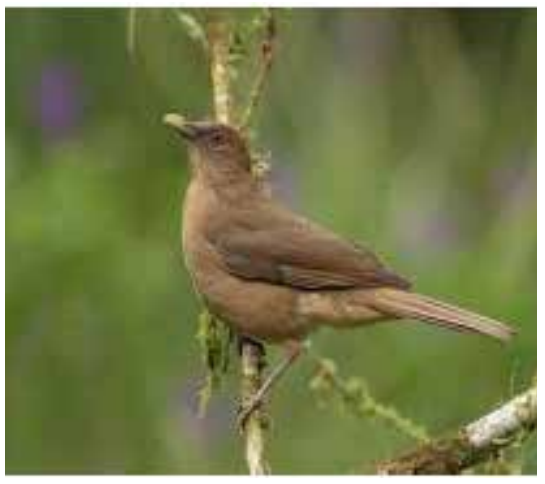

Figura 2

Figura 2: Quiscalus mexicanus: Su hábitat suele ser las áreas agrícolas y las afueras, donde se alimenta de frutas, semillas e invertebrados. 


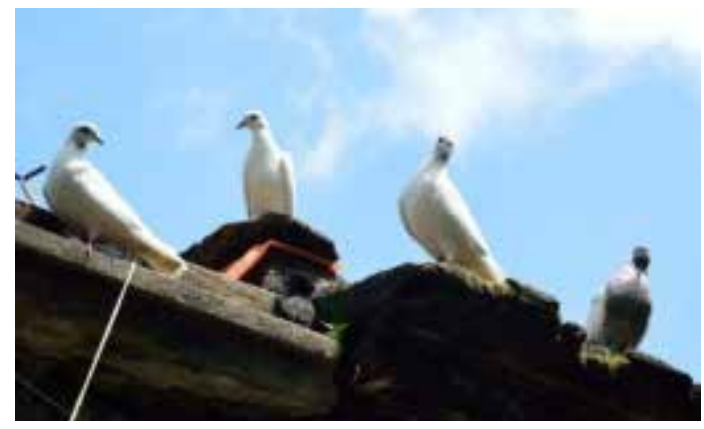

Figura 3

Figura 3: Paloma (Columbidae): Algunas especies se han adaptado al entorno urbano, hasta tal punto que se han convertido en un problema en ciudades.

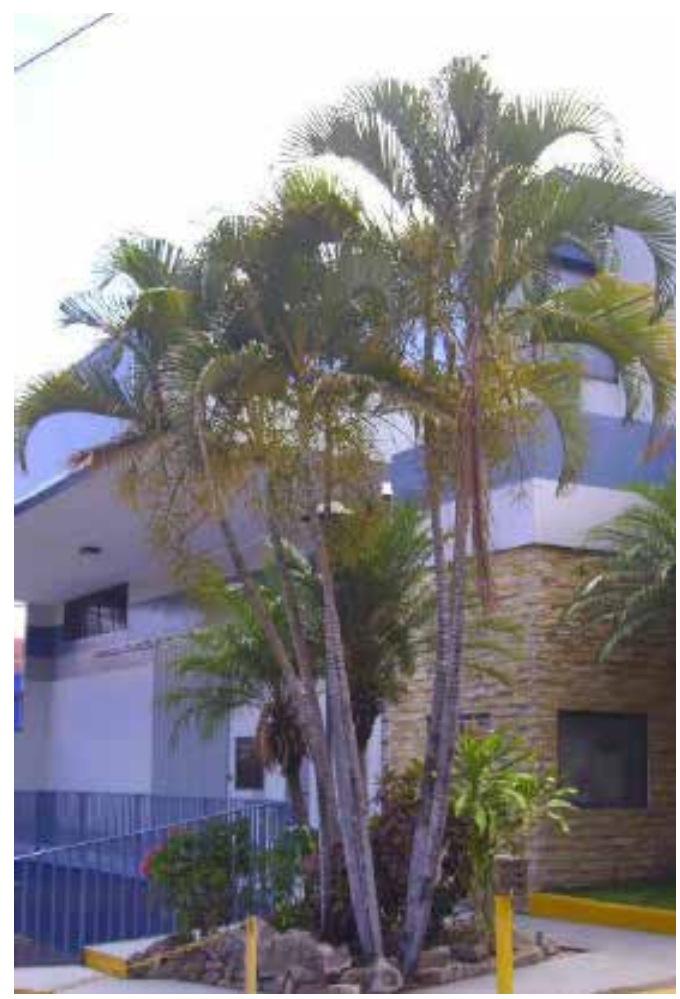

Foto 2 
Foto 2: Palmera (Dypsis lutescens): palmera utilizada en la decoración de interiores por su gran valor ornamental.

Produce largas inflorescencias muy ramificadas, pero en interior no suelen aparecer.

Con la edad produce menos tallos pero éstos adquieren mucha robustez y una pátina grisácea, además de anillos más marcados que semejan a la caña de bambú (Planta y flor, 2014).

Foto tomada en las oficinas de COCESNA.

Animales atraídos: Palomas.

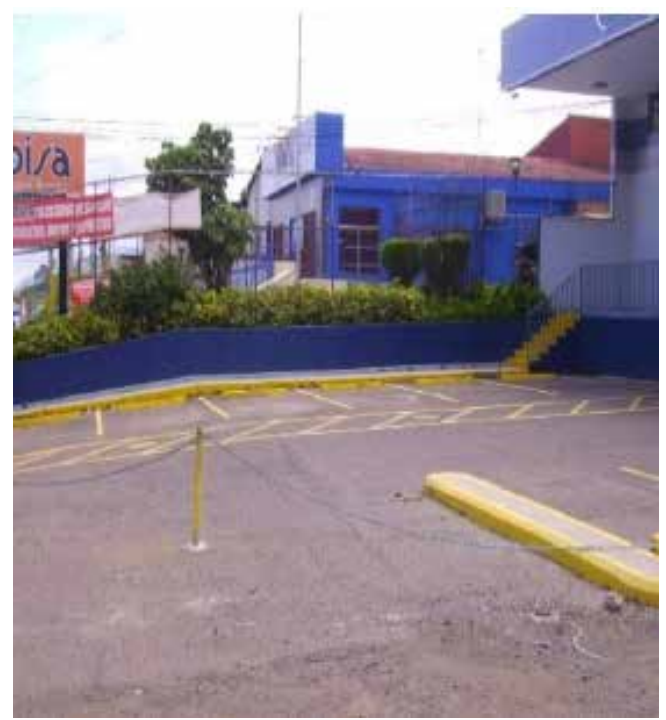

Foto 3

Foto 3: Ficus Benjamina: De la Familia, Moraceae que desarrolla raíces aéreas. Sus flores son pequeñas, en inflorescencias a modo de siconos, de color blanquecino- amarillento. Sin importancia ornamental. Frutos: Pequeño, esférico y con un gracioso color rojo sangre que lo hace resaltar aún más. No necesita más que una ligera poda de formación. En primavera podar $2 / 3$ de las ramas desnudas para que crezcan más ramificadas. Plagas y enfermedades: cochinillas, pulgones, arañas rojas y roya (Infojardín, 2014). 
Foto tomada en el estacionamiento de COCESNA. Animales atraídos

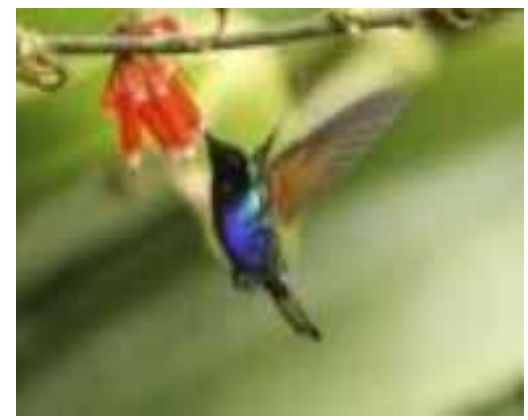

Figura 4

Figura 4: Colibrí (Trochilinae) Son pequeñas aves nativas de México, América Central y la parte norte de Sudamérica. Construyen nidos en forma de copa, en los que suelen poner 2 huevos, los cuales son de color blanco.

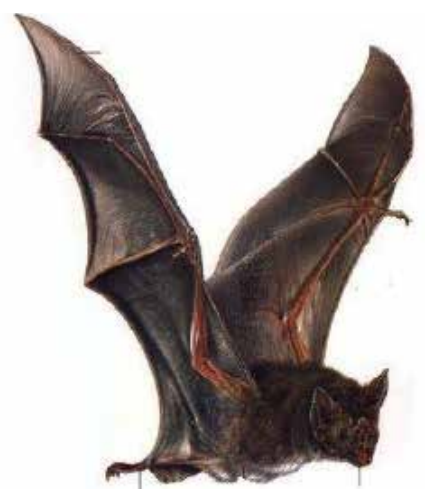

Figura 5

Figura 5: Murciélago (Murciélago): Ocupan nichos en todos los hábitats, excepto en las regiones polares, los océanos o las montañas más altas. La mayor parte son insectívoros, pero tienen una amplísima variedad de dietas; algunos se especializan en una gama de alimentos relativamente estrecha y otros son omnívoros. Casi todos los murciélagos comen de noche y descansan de día, en sitios muy variados según las especies, como cuevas, edificaciones, agujeros, grietas o al aire libre. 


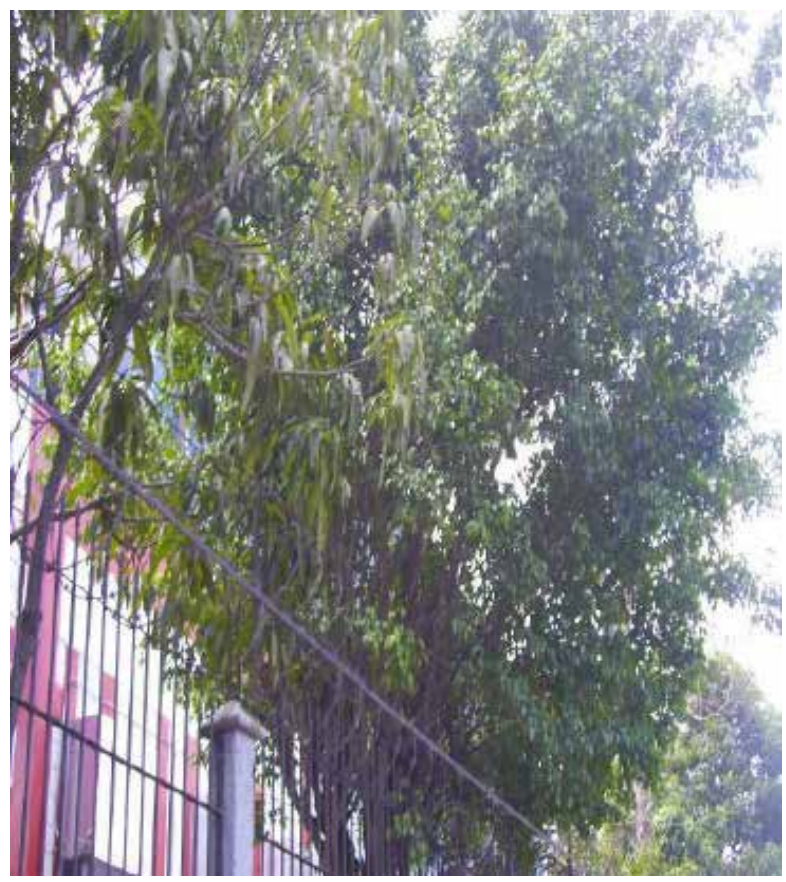

Foto 4

Foto 4: Mango (Familia Anacardiaceae): Árbol de tamaño mediano, de 10-30 m de altura. Fruto: Se trata de una gran drupa carnosa que puede contener uno 0 más embriones. Posee un mesocarpio comestible de diferente grosor según los cultivares y las condiciones de cultivo. Su peso varía desde $150 \mathrm{~g}$ hasta $2 \mathrm{~kg}$. Su forma también es variable, pero generalmente es ovoide-oblonga, notoriamente aplanada, redondeada, u obtusa a ambos extremos, de 4-25 cm. de largo y 1.5-10 $\mathrm{cm}$. de grosor. El color puede estar entre verde, amarillo y diferentes tonalidades de rosa, rojo y violeta. Poseen flores con 5 estambres fértiles.

Foto tomada entre COCESNA y "Pollo Yamal"

Aves atraídas: Palomas 


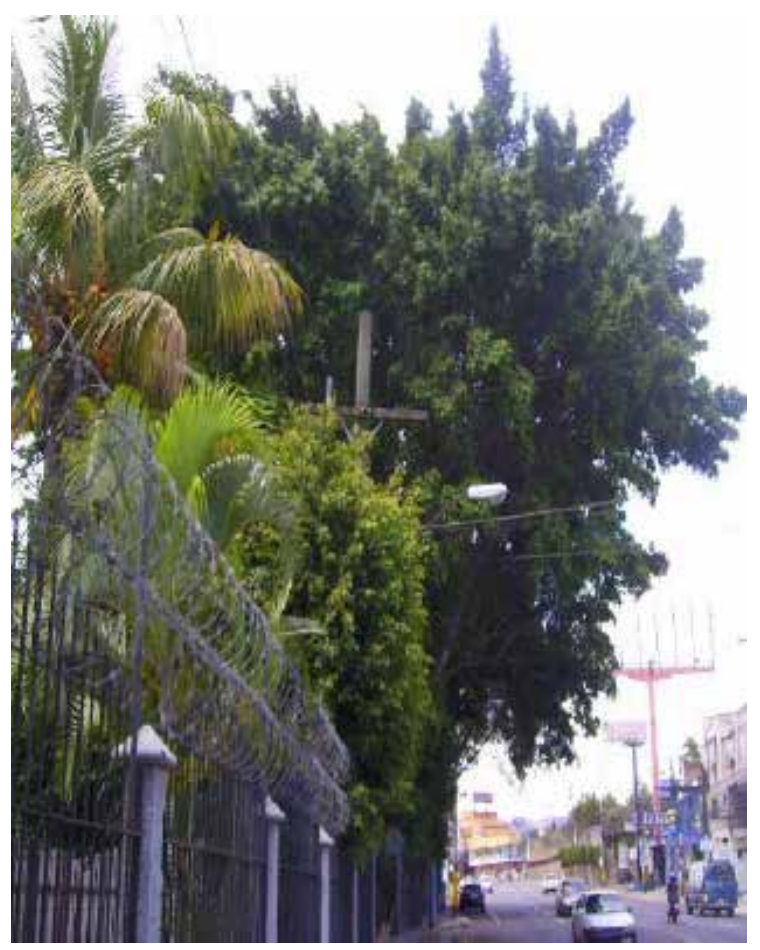

Foto 5

Foto 5: Cocos nucifera: Las hojas de esta planta son de gran tamaño de hasta $3 \mathrm{~m}$ de largo y su fruto, el coco, contiene a la semilla más grande que existe. El cocotero es una sola especie con múltiples variedades, diferenciadas básicamente por el color del fruto (amarillo o verde). El rasgo común y característico de todas ellas es el sabor de fruto, cuya características es que es agradable, dulce, carnoso y jugoso.

Las flores del cocotero son poligamomonoecias, con las flores masculinas y femeninas en la misma inflorescencia. El florecimiento ocurre continuamente, con las flores femeninas produciendo las semillas.

Sirve como materia prima para producir margarina, jabón y vino (wikipedia, 2014). Foto tomada en la zona aduanal, a la par de la Empresa DHL.

Aves atraídas: Murciélagos 


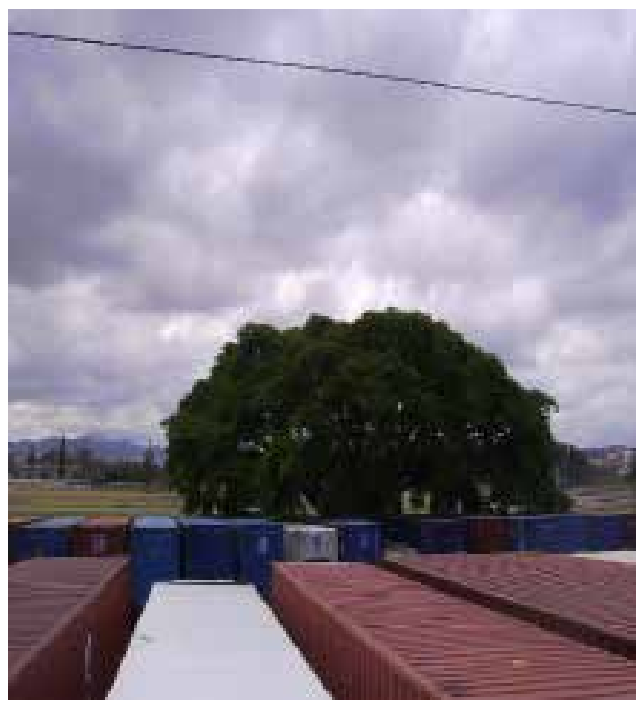

Foto 6

Foto 6: Parqueo de contenedores, puede ser refugio de animales roedores u otros que puedan entrar en la pista de aterrizaje.

Foto tomada entre Aeroplaza y la Empresa de envíos DHL. Animales atraídos:

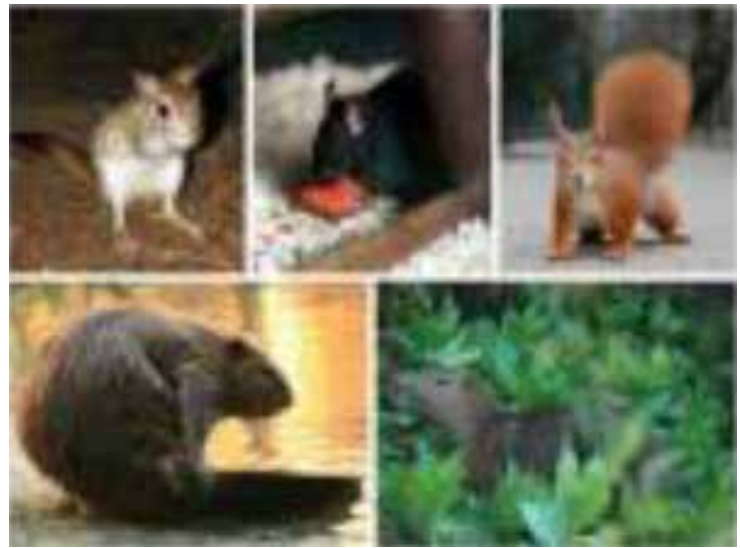

Figura 6 
Figura 6: Rodentia (Ratas, ratones, ardillas, hamsteres y conejillos de Indias). Muchos roedores se alimentan de semillas o plantas, aunque algunos tienen dietas más variadas. Algunas especies han sido consideradas históricamente como plagas, comiendo semillas almacenadas o esparciendo enfermedades. Son de adaptación muy versátil.

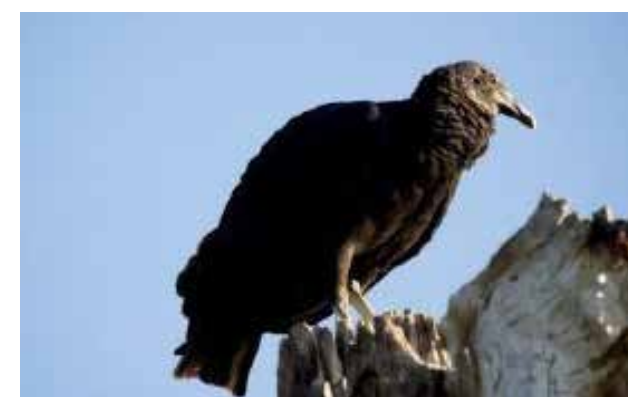

Figura 7

Figura 7: Zopilote (Coragyps atratus): Es un carroñero, pero también se alimenta de huevos y animales recién nacidos. En lugares poblados por el hombre se alimenta además en basureros

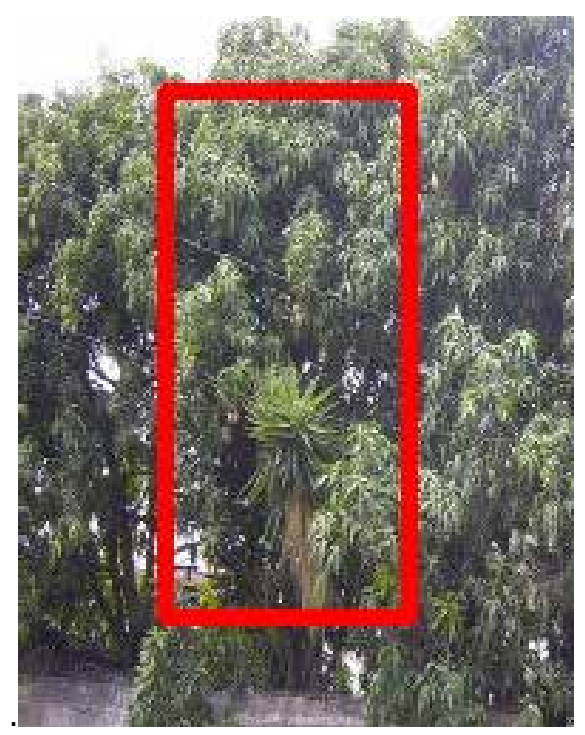

Foto 7

Foto 7: Flor de Izote (Yucca guatemalensis): Familia: Agaváceas. Planta perenne de hasta $10 \mathrm{~m}$ de altura. Las hojas, situadas en los extremos de los tallos y fibrosas, son alargadas (de 0,5 a 1,2 m de longitud y de 5 a $7 \mathrm{~cm}$ de ancho), cortantes y con 
los bordes ligeramente dentados y la punta muy aguda, pero no punzante, ya que no dispone de espina terminal. Las flores, acampanadas, de color blanco o crema y de unos $4 \mathrm{~cm}$ de largo, aparecen en densas panículas. El fruto, ovoide, es bastante seco y de color negro. Época de floración: Abril- mayo; Época de fructificación: Mayo-junio. En la zona de origen, las hojas se usan para fabricar tejidos y en cestería y las flores y los brotes tiernos se consumen como verdura (Medioambiente, 2014). Foto tomada en el Zona de parqueo de la Empresa DIVESA. Animales Atraídos:

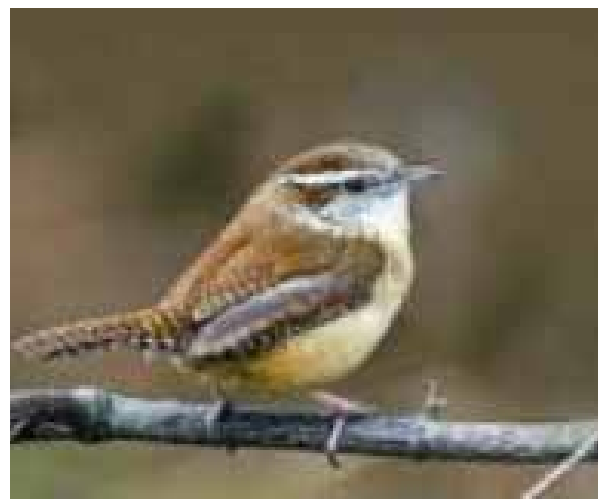

Figura 8

Figura 8: Pájaro Cucarachero (Campylorhynchus griseus): El cucarachero chupa huevos, cucarachero currucuchú (Campylorhynchus griseus) es una especie que puebla las zonas de matorral. Se alimenta de insectos y de sus huevos, los que busca entre los troncos aprovechando su largo pico; también puede ingerir arácnidos.

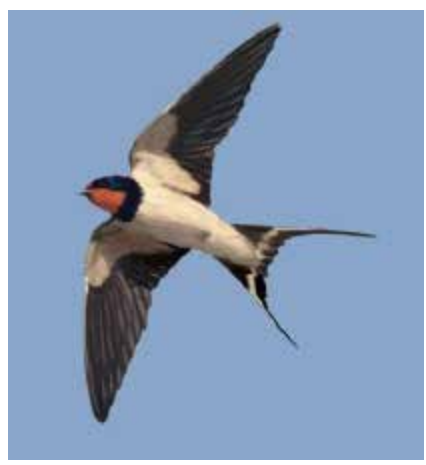

Figura 9 
Figura 9: Golondrina (Hirundus Rustica): La golondrina común es un ave de campo abierto que normalmente utiliza estructuras construidas por el hombre para reproducirse y que, en consecuencia, se ha diseminado con la expansión humana. Construye nidos en forma de taza, con bolitas de barro en graneros y construcciones similares y se alimenta de insectos que atrapa en vuelo.

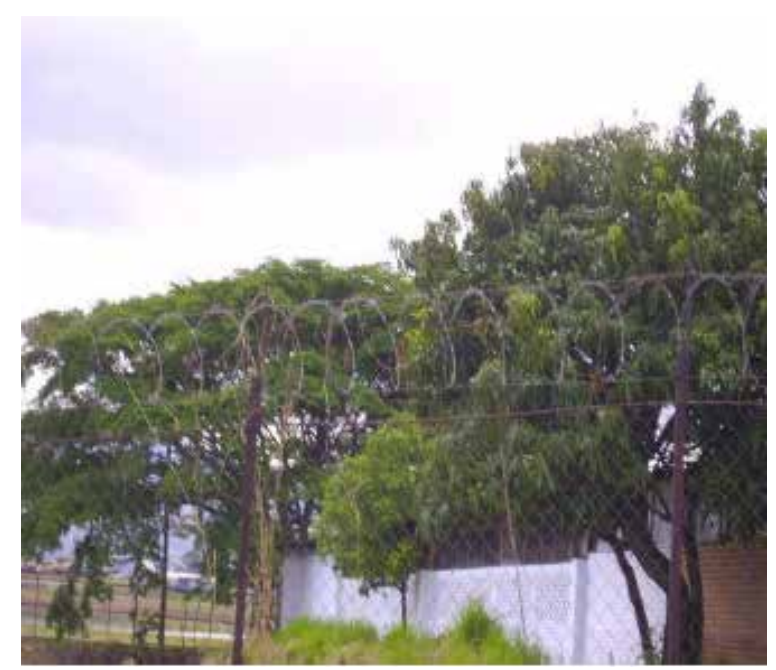

Foto 8

Foto 8: Guanacaste (Enterolobium cyclocarpum): Es una de las dos especies conocidas como "oreja de elefante" en varios países latinoamericanos y "árbol de Guanacaste" en Honduras. El fruto en legumbre tiene forma de círculo helicoidal, de modo que el ápice toca casi con la base. Hay ejemplares de $4 \mathrm{~m}$ de diámetro. Alcanza alturas de 16 a $28 \mathrm{~m}$ con una gran expansión del ramaje. Las hojas recuerdan al Tamarindo.

Las semillas de Enterolobium cyclocarpum son fáciles de hacer germinar en 3 a 4 semanas, y 1 a 2 con asistencia. A veces se usa como árbol de ornato.

Foto tomada en el costado Norte del estacionamiento de contenedores en el límite con la propiedad contigua.

Animales atraídos: Paloma, Quiscalus mexicanus y zorzal. 


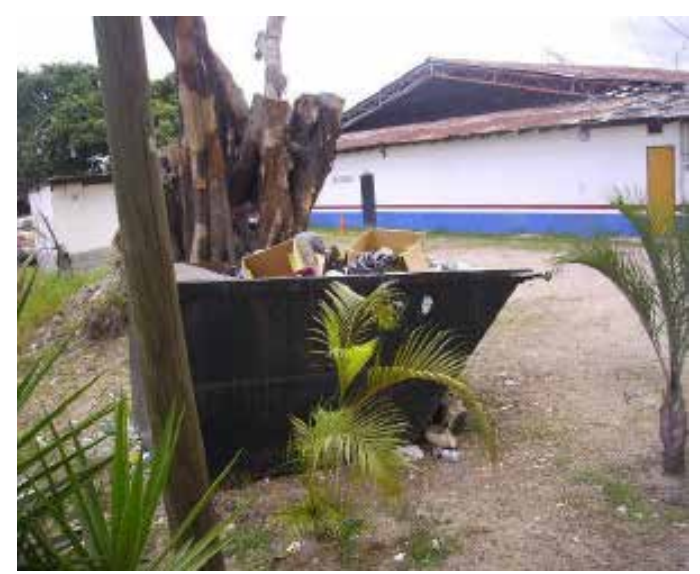

Foto 9

Foto 9: Basurero destapado, en el fondo se pueden ver, Arecas, Izote y Ficus (aparece cortado en la foto).

Foto tomada en los predios de la Empresa DIVESA.

Aminales atraídos: Palomas, pájaro cucarachero, zopilote, quiscalus mexicanus, roedores.

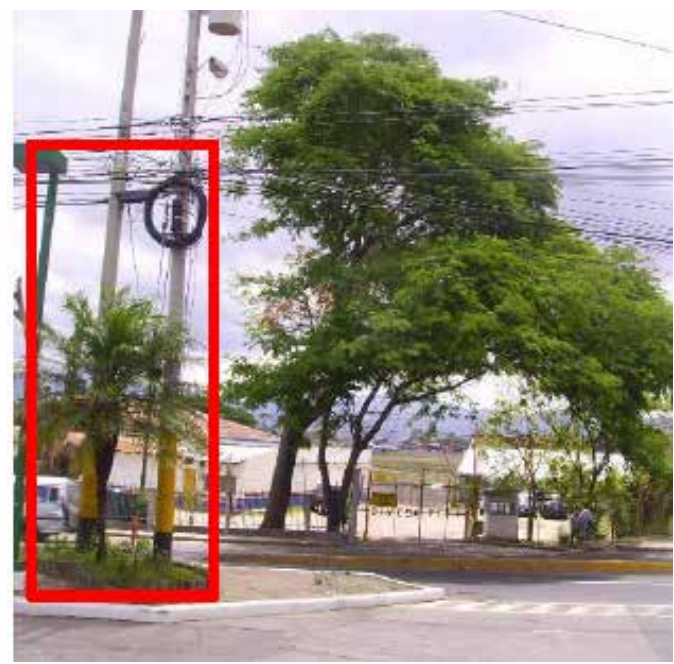

Foto 10 
Foto 10: Palmera (Phoenix Canariensis): Perteneciente a la familia Phoenix spp, Debido a su belleza, facilidad de adaptación y resistencia al frío es una de las palmeras que más se usa en jardinería. Las flores se disponen en densos racimos anaranjados. Frutos más pequeños que los dátiles. Fotografía tomada en los locales de DIVESA. Animales atraídos: Zorzal, quiscalus mexicanus, paloma.

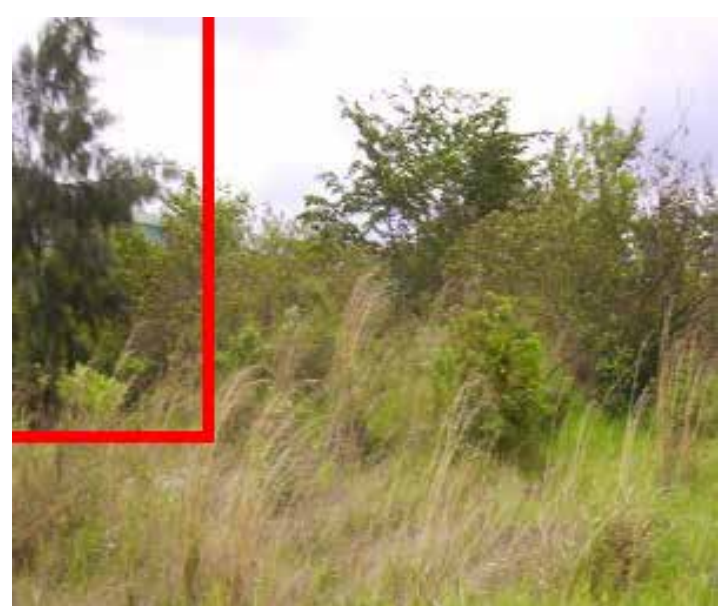

Foto 11

Foto 11: Área verde boscosa (al fondo): Foto tomada desde el extremo Sur del Aeropuerto Toncontín; en ella se muestran ambos costados del portón que divide la FAH y la Colonia Godoy cerca del extremo Sur de la pista.

Animales atraídos: roedores y distintos tipos de pájaros. 


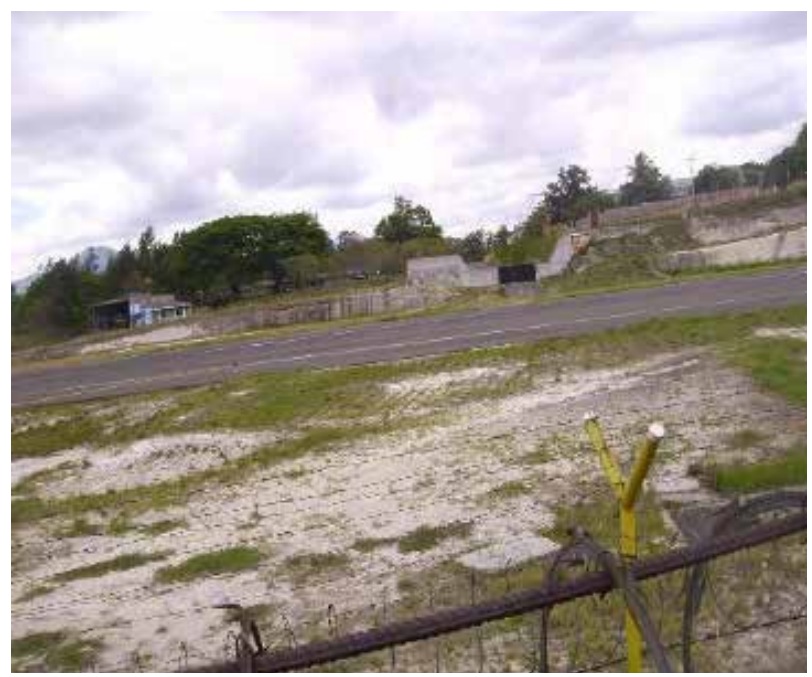

Foto 12

Foto 12: Vegetación de diversos tipos y, en el recuadro, Pino australiano (Casuarina equisetifolia); Muy útil para reforestación rural y urbana en trópicos, subtrópicos y regiones templadas; es un árbol de crecimiento rápido.

Se pueden ver además en la ilustración el Capulín (muntingia calabura) que se encuentra comúnmente en los bordes de selvas bajas, así como en la vegetación riparia acahuales, potreros y otras zonas perturbadas, tiene frutos pequeños y dulces atractivos para las aves. Se puede contemplar también zacate jaragua (hyparrhemia rufa).

Foto tomada en el extremo Sur de la pista a la par de boulevard Comunidad Económica Europea.

Animales atraídos 


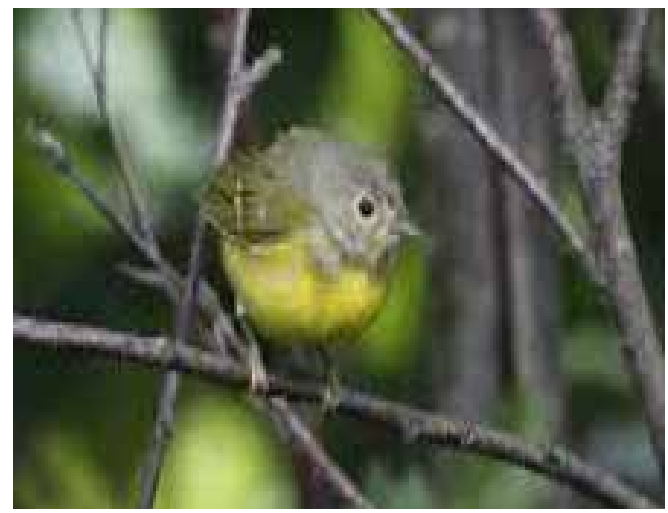

Figura 10

Figura 10: Chipe (Oreothlypis ruficapilla) ave migratoria que anida en Canadá y Estados Unidos y pasa el invierno en México y Centroamérica. Forma grupos alimenticios con otras especies.

Busca alimento entre los árboles o los arbustos. Se

alimenta principalmente de insectos. Este ambiente de maleza atrae además otros pájaros pequeños y roedores.

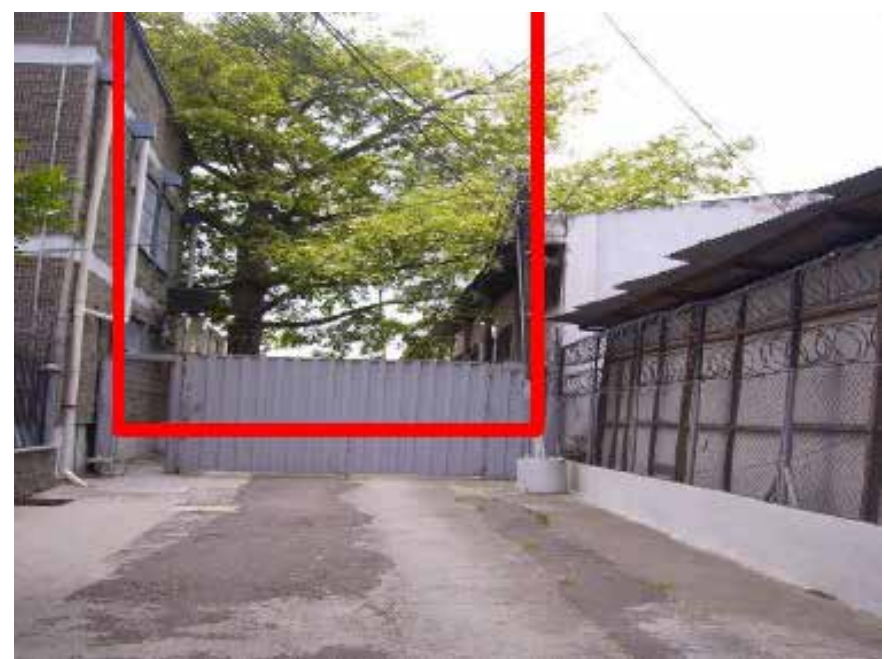

Foto 13 
Foto 13: Ceiba (Ceiba pentandra): Es un árbol de la zona intertropical del orden Malvales y de la familia Malvaceae y originario de la región de Mesoamerica. El árbol alcanza 60 a 70 metros de altura, con un tronco grueso que puede llegar a medir más de $3 \mathrm{~m}$ de diámetro, con raíces tabulares. El tronco y muchas de sus ramas mayores están densamente pobladas de espinas largas y robustas. Los árboles adultos producen varios cientos de frutos. Sus cápsulas contienen semillas que se encuentran rodeadas por una fibra amarillenta de aspecto algodonoso, que es una mezcla de lignina y de celulosa.

Foto tomada entre las oficinas de COCESNA y la zona aduanal al Sur del Aeropuerto Toncontín. Animales atraídos: Zopilotes, gavilanes.

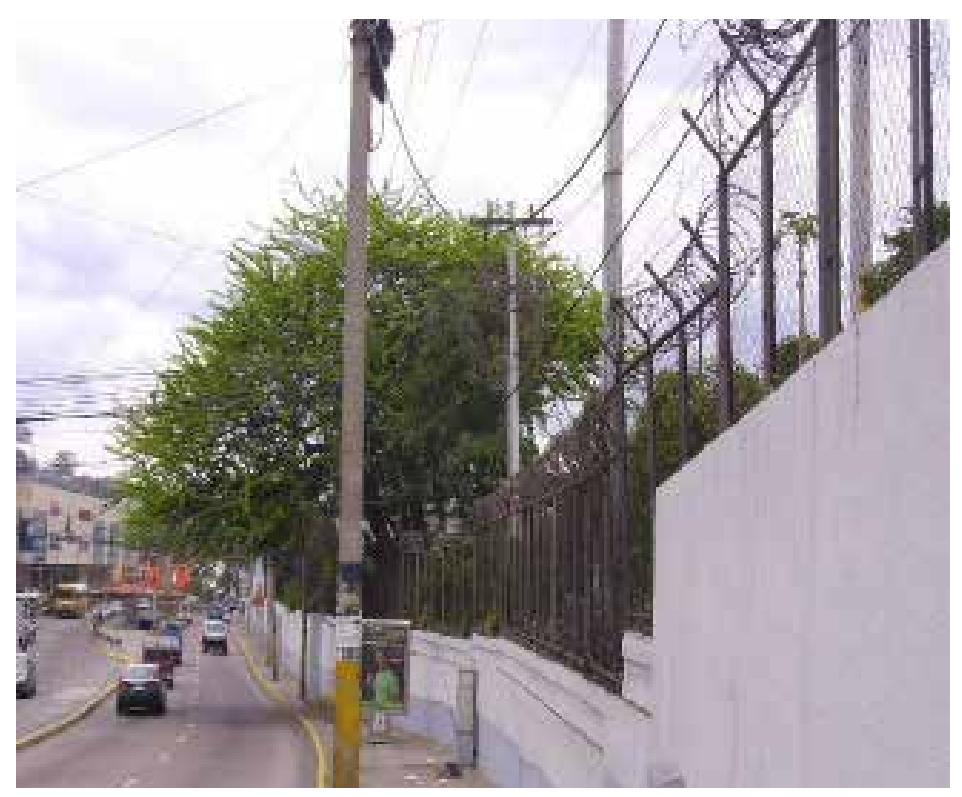

Foto 14

Foto 14: Jícaro (Crescentia alata). Es una especie de pequeño árbol perteneciente a la familia de las bignoniáceas (Familia de plantas de flor perteneciente al orden Lamiales). Es un árbol silvestre que mide entre 8 y $14 \mathrm{~m}$ de altura y hasta $25 \mathrm{~cm}$ de diámetro. Florece todo el año. Las hojas son ovales y salen tres de un mismo fascículo en el centro con medidas de 4 a $6.5 \mathrm{~cm}$ de largo. Las Flores son de color amarillento y violáceo; en ocasiones con franjas de color rosado y morado. Las 
semillas son comestibles y de alto contenido de proteínas con un sabor dulce como de regaliz. Foto tomada frente a dependencias de la policía nacional (cerco de color azul y amarillo).

Animales atraídos: Palomas.

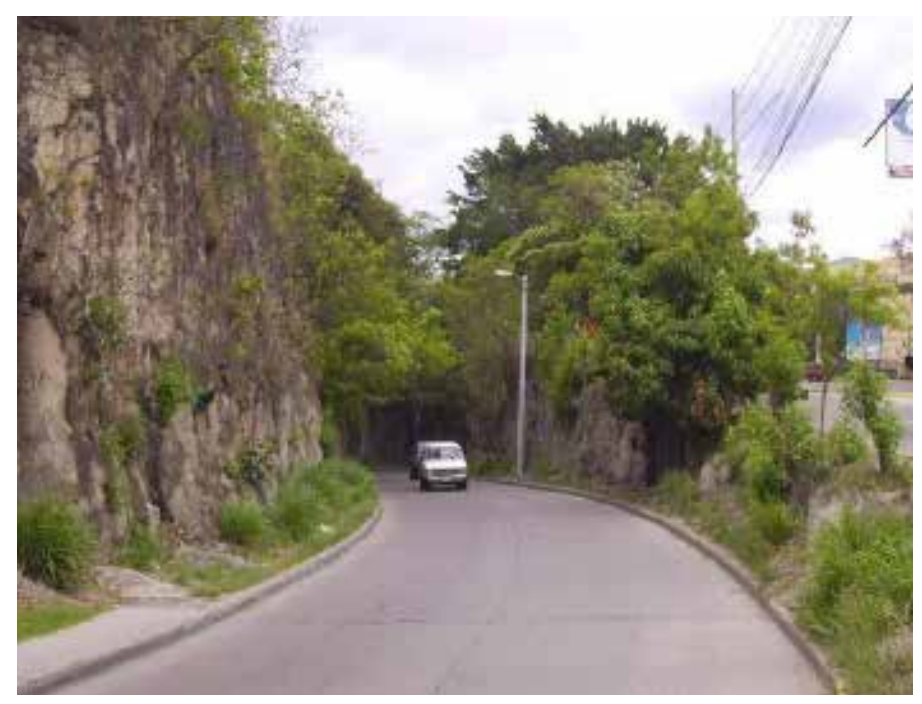

Foto 15

Foto 15: Zona con árboles y arbustos de distinto tipo: Foto tomada en la calle-túnel que comunica la zona del Pedregal, Las Brisas y con Las Torres, Los Robles y otros.

Animales atraídos: distintos tipos de pájaros y roedores. 


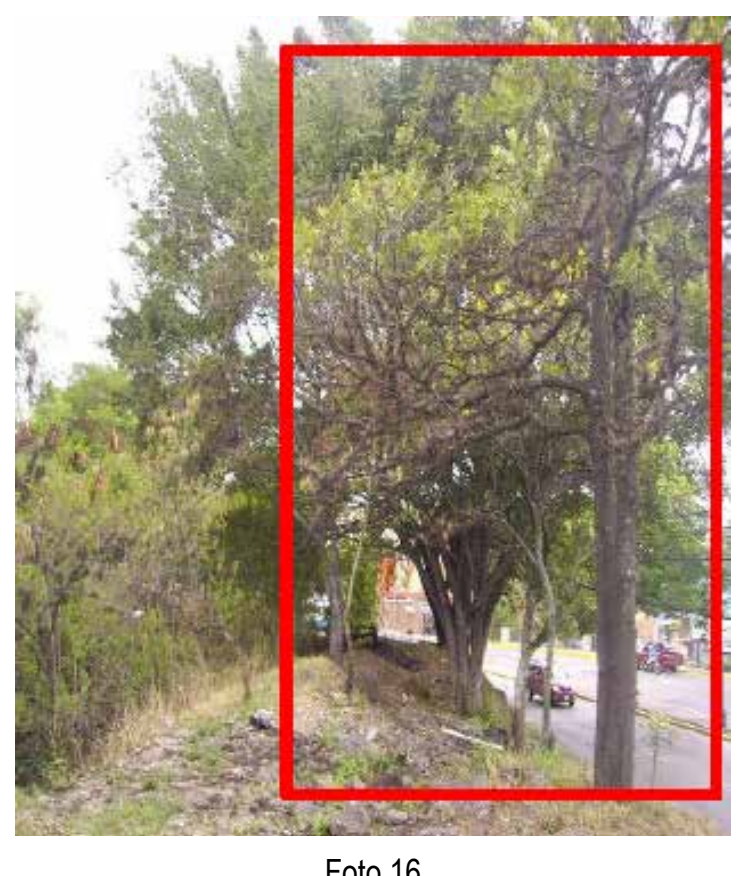

Foto 16: Negrito o Aceituno (Simaruba glauca): Los frutos que produce son comestibles, y son fuente de alimento para una variedad de aves y otros animales.

La regeneración natural sucede cuando aves y reptiles expulsan la semilla después de haberse

alimentado de la pulpa dulce del fruto. Se nota en la foto también la Leucaena, un género de cerca

de 24 especies de árboles y arbustos, tiene frutos

y semillas comestibles, usadas en alimentación forrajera animal, en abonos verdes, conservación de suelos, semillas para collares, fuente vegetal de aceite combustible para energía (wikipedia,2014). 
Animales atraídos:

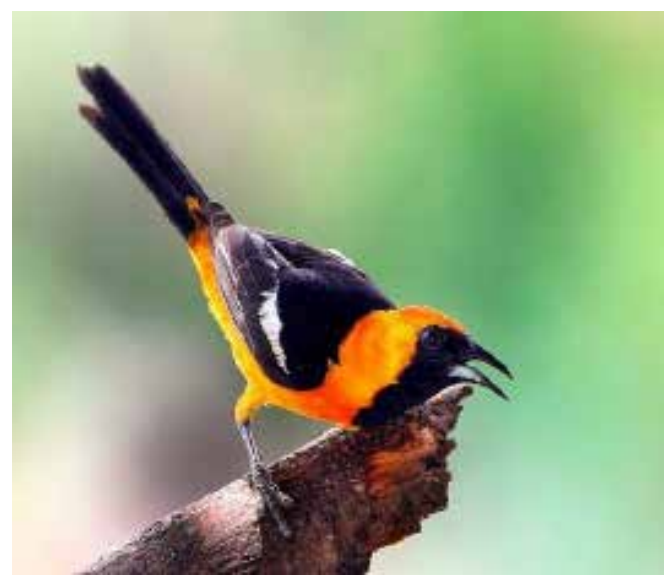

Figura 11

Figura 11: La chorcha (Icterus cucullatus): Es originaria de América del Norte y Centroamérica. Su hábitat de cría son las áreas abiertas arboladas, especialmente palmeras.

\section{Conclusiones}

- Los aportes de la presente investigación se limitan a la recolección de alguna de la abundante bibliografía existente sobre el tema y a la propuesta de unos elementos metodológicos que pueden ayudar a encuadrar el tema del peligro aviar y de fauna en general en el Aeropuerto Internacional Toncontín, para tener un estudio que incorpore datos de campo se requiere de más tiempo y sobre todo de la colaboración en todo el proceso de investigación de un equipo integrado por especialistas del campo de la biología que profundicen en una serie de temas que sólo fueron mencionados.

- El principal peligro aviar en el aeropuerto Internacional Toncontín se da por los zopilotes (Coragyps atratus); lo cual no significa que no haya peligros latentes por la presencia de otras especies de menor tamaño y peso que llegan a las cercanías y al recinto del aeropuerto en busca de alimentación, agua y refugio

- La presencia de zopilotes está siendo incentivada por la cercanía con el Aeropuerto de amplias zonas urbanas (comercial, industrial y residencial), con manejo a veces deficiente de residuos y reciclaje, el cual lleva a la generación 
de nuevos vertederos ilegales en las áreas de aproximación del aeropuerto Internacional Toncontin.

- El abordaje de una siguiente investigación puede partir de los datos disponibles de forma dispersa entre distintos actores relacionados con temas de manejo de desechos sólidos en la ciudad de Tegucigalpa, puestos que estos lugares muy frecuentados por el zopilote común; a este respecto puede ser mucha utilidad el inventario sobre botaderos en Tegucigalpa ofrecido por Kazla Suazo Medina (Medina, 2012).

- El Coragyps atratus goza de cierto estatus de importancia en el equilibrio ecológico del municipio del Distrito Central, por lo que su manejo requiere medidas especiales y bien coordinadas.

- El peligro de fauna terrestre no tiene reportes o estadísticas, es más bien un peligro latente, el cual requiere mayor énfasis en su estudio particular. El aeropuerto Internacional Toncontín requiere conformar un equipo especializado en la atención del peligro de fauna y su control.

- La valla perimetral se encuentra en buen estado, una incursión de fauna terrestre sería un caso fortuito. En las observaciones realizadas no se encontró la presencia de animales domésticos (perros, gatos) o silvestres (venados) dentro del recinto aeroportuario, más allá de algunas aves de pequeño calado.

- En la extremo Norte del Aeropuerto que colinda con las Colonias El Pedregal y se presentan un tipo de vegetación que podría atraer aves de peso y envergadura considerables.

- Por los momentos en el Aeropuerto Toncontín con respecto al peligro aviar se está viviendo una etapa de organización e información; se han sostenido reuniones con los distintos sectores que pueden estar involucrados en la conformación de un comité de peligro aviar y, por otra parte se ha hecho un trabajo de prevención auxiliándose del equipo de SMS.

- En el extremo Sur se constató abundante maleza con especies de distintos tipos de vegetación con potencial de atracción de aves; además se pudo observar al menos un contenedor de basura sin tapadera, que podría contener desechos con atractivo potencial para aves oportunistas (zopilotes, caracará, zanates, tordos); esta situación se da de manera relevante en el botadero situado en los predios de la Fuerza Aérea Hondureña. 
- Si bien el presente estudio no tiene los alcances para ocuparse de los peligros latentes en los botaderos que están en los conos de aproximación del Aeropuerto, la consulta a fuentes secundarias y los resultados de un recorrido hecho por el biólogo de la Concesionaria, hace ver clara la necesidad de hacer un estudio más detenido que se ocupe de estas zonas.

- Un estudio más profundo sobre el tema debería centrarse en las aves, más que en otros animales; en cuanto la terminología y metodología podría ser útil la propuesta por Mongenroth (2013) en donde se propone estudiar aspectos como masa corporal, tendencia a agruparse, tamaño del grupo, presencia/fenología, participación en incidentes anteriores, presencia de hábitats, sobrevuelos en los alrededores, ocurrencia en la región, tiempo en el aire.

\section{Bibliografía}

- Agencia Estatal de Seguridad Aérea. (2013). Guía para la elaboración de estudios de fauna y sus habitats en entornos aeroportuarios. Madrid, España: Agencia Estatal de Seguridad Aérea.

- Árboles ornamentales. (28 de abril de 2014). Obtenido de www.arbolesornamentales.es/Myrtaceae.htm

- Dirección General de Aeronáutica Civil. (2008). Regulación de Aeronáutica Civil 139. Tegucigalpa : DGAC.

- Gill, F. (1995). Ornithology. New York : W.H. Freeman and Co.

- Infojardín. (27 de abril de 2014). Obtenido de fichas.infojardin.com/ficus-benjamina-matapalo- arbol-benjamin.html

- Medina, K. G. (2012). Análisis del riesgo social y ambiental de los botaderos de desechos sólidos en Tegucigalpa. Tegucigalpa.

- Medioambiente. (15 de mayo de 2014). Obtenido de mediambient.itineraris. bcn.cat/es/node/95/360

- OPAIN, S.A. (2010). Programa de reducción de impactos con fauna Aeropuerto Internacional El Dorado. Bogotá: OPAIN.

- Organización para la Aviación Civil Internacional. (1991). Manual de servicios de Aeropuertos (Doc 9137-AN/898). Parte 3 Reducción del Peligro que representan las aves. Montreal: $\mathrm{OACl}$. 
- Planta yflor.(27 de abril de 2014). Obtenido de plantayflor.blogspot.com/2013/05/ dypsis- lutescens.html

- Roberto Hernandez Sampieri, C. F. (2006). Metodología de la Investigación. México: McGraw-Hill.

- wikipedia.(27 de abril de 2014). Obtenido de es.wikipedia.org/wiki/Cocos

- wikipedia.(12 de mayo de 2014). Obtenido de es.wikipedia.org/wiki/Leucaena. 